\title{
ATP7B expression in human glioblastoma is related to temozolomide resistance
}

\author{
F.M. MOINUDDIN ${ }^{1,2}$, HIROFUMI HIRANO ${ }^{1}$, YOSHINARI SHINSATO ${ }^{2,3}$, \\ NAYUTA HIGA $^{1,2}$, KAZUNORI ARITA $^{1}$ and TATSUHIKO FURUKAWA ${ }^{2,3}$ \\ Departments of ${ }^{1}$ Neurosurgery and ${ }^{2}$ Molecular Oncology; ${ }^{3}$ Center for The Research of Advanced Diagnosis and Therapy \\ of Cancer, Graduate School of Medical and Dental Sciences, Kagoshima University, Kagoshima 890-8544, Japan
}

Received February 2, 2017; Accepted September 22, 2017

DOI: $10.3892 / \mathrm{ol} .2017 .7249$

\begin{abstract}
Glioblastoma multiforme (GBM) is one of the most aggressive types of brain malignancy, with resistance to chemotherapy being a primary treatment obstacle. ATPase copper transporting $\beta$ (ATP7B) is involved in multidrug resistance; however, its expression in GBM remains to be evaluated. In the present study, GBM specimens from 79 patients who underwent gross total tumor removal followed by concomitant temozolomide (TMZ) chemotherapy and radiotherapy were assessed immunohistochemically. The association between the overall survival times of patients and the expression of ATP7B in neoplastic cells was evaluated. In 12/79 tumors $(15.2 \%)>10 \%$ of neoplastic cells were immunohistochemically-positive for ATP7B, and categorized as high-ATP7B GBM. In the remaining 67 tumors (84.8\%) the rate of ATP7B-positive cells was $<10 \%$ and recorded as low-ATP7B GBM. The median overall survival times of patients with high- and low-ATP7B GBM were 14.6, and 24.7 months, respectively. High expression of ATP7B was identified to be associated with shorter overall survival times (hazard ratio, 0.452 ; 95\% confidence interval, 0.206-0.994; $\mathrm{P}=0.048$ ). Of the 79 patients, 12 underwent a second operation due to recurrence. These tissue samples were also subjected to immunohistochemical study. The ATP7B positivity rate of tumor cells obtained during the second surgery was significantly higher compared with that in the first surgery ( $9.17 \pm 2.56$ vs. $2.75 \pm 0.55 \% ; \mathrm{P}=0.008)$. In addition, two ATP7B-transfected GBM cell lines were identified to be significantly resistant (3.8- and 1.7-fold, respectively) to TMZ compared with the control cell line. The findings of the present study suggest that ATP7B influences GBM resistance to TMZ.
\end{abstract}

Correspondence to: Dr Hirofumi Hirano, Department of Neurosurgery, Graduate School of Medical and Dental Sciences, Kagoshima University, 8-35-1 Sakuragaoka, Kagoshima 890-8544, Japan

E-mail: hirahira@m2.kufm.kagoshima-u.ac.jp

Key words: ATP7B, copper transporter, glioblastoma multiforme, temozolomide resistance

\section{Introduction}

Glioblastoma multiforme (GBM) remains incurable despite advanced treatments including surgery, chemotherapy, and irradiation (1). Temozolomide (TMZ), the most widely used chemotherapeutic agent, prolonged the median survival of GBM patients by only up to 14.6 month (2). TMZ resistance is one of the greatest obstacles to successful GBM treatment; the tumors tend to recur within a few months and result in death (3). Several factors contribute to the regulation of the acquired and intrinsic pathway of resistance to chemotherapy (4). A P-type ATPase copper transporter ATP7B plays a role in the elicitation of multi-drug resistance (5); its expression was elevated in human malignancies including ovarian-, gastric-, and breast cancer (6-8).

We investigated the expression of ATP7B in GBM and its role in the resistance of glioblastoma to TMZ. We show for the first time that the high expression of ATP7B is correlated with the poor overall survival of GMB patients and that ATP7B over-expressing cell lines are resistant to TMZ.

\section{Materials and methods}

Patients and tissue samples. Surgical specimens from 79 consecutive GMB patients who underwent total tumor removal surgery from 2007 to 2015 at the Department of Neurosurgery, Kagoshima University Hospital, were available for immunohistochemical study. All were treated with TMZ $\left(75 \mathrm{mg} / \mathrm{m}^{2} /\right.$ day) concurrently with conventional radiation therapy conventional radiation $40 \mathrm{~Gy}$ plus CyberKnife $35 \mathrm{~Gy} / 5$ fractions. This was followed by maintenance TMZ treatment $\left(150 \mathrm{mg} / \mathrm{m}^{2}\right.$ for 5 consecutive days of every 28 days). We retrospectively reviewed the clinical records of all patients. Of these, 12 underwent the second operation followed by same adjuvant therapy due to the recurrence; tissue samples from the 1st and 2nd surgical procedure were studied.

Our retrospective analysis was approved by the ethics committee of Kagoshima University Hospital (reference 27-05). The authors certify that the study involving human subjects was conducted in accordance with the 2013 Declaration of Helsinki. The data we collected are routinely obtained and are essential for the adequate management of glioblastoma. They were analyzed anonymously in a linkable fashion to protect 

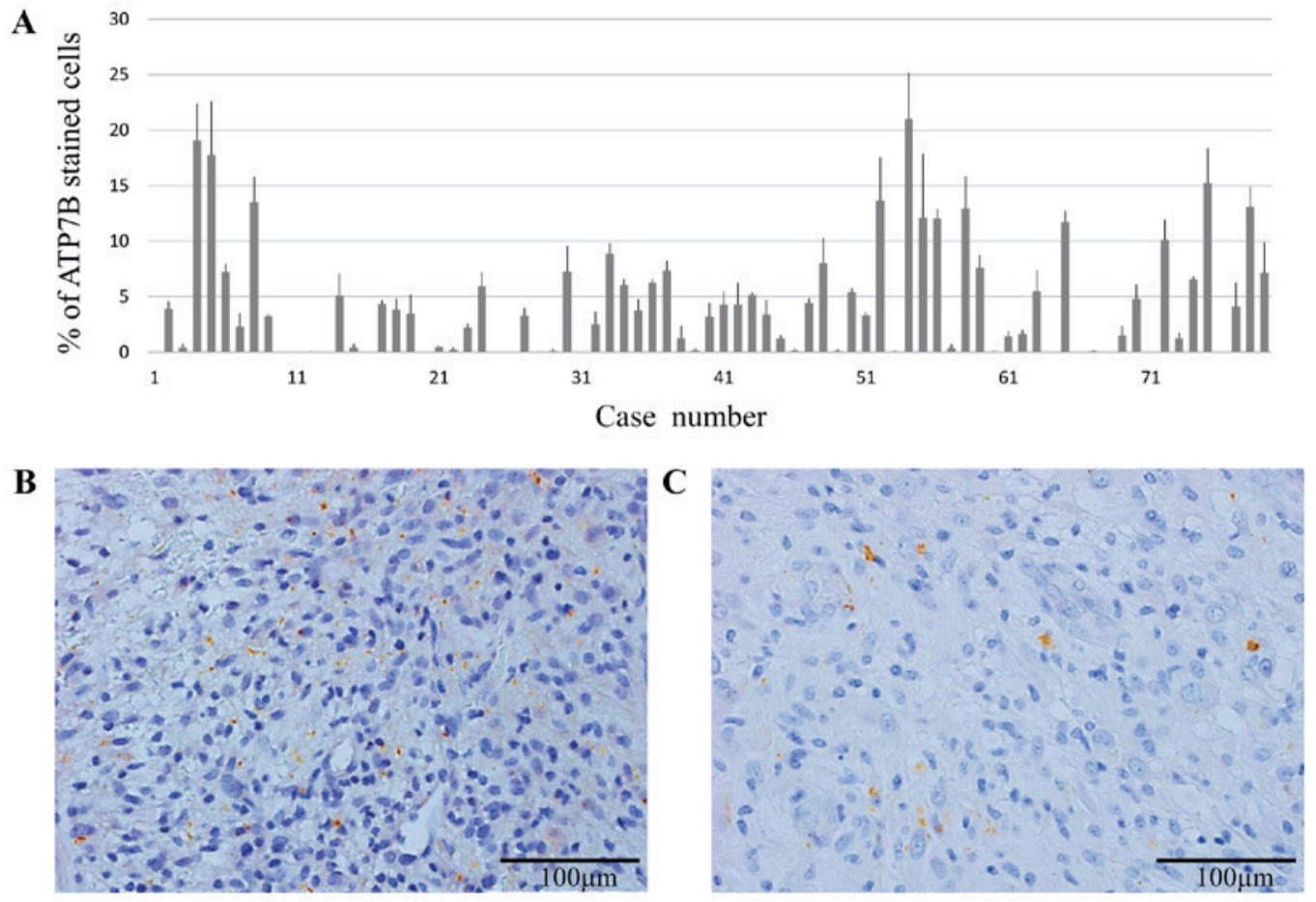

Figure 1. Immunohistochemical staining of glioblastoma multiforme (GBM) specimens using anti-ATP7B antibody. (A) Percentage of cells expressing ATP7B protein in each of 79 GBM tumors. Percentage \pm SD is from three microscopic fields (magnification $x 400$ ) examinations. (B) High-ATP7B GBM $(>10 \%)$ stained with anti-ATP7B antibody (Bar indicates $100 \mu \mathrm{m})($ C) Low-ATP7B GBM $(<10 \%)$ stained with anti-ATP7B antibody (Bar indicates $100 \mu \mathrm{m})$.

patient privacy. Informed patient consent was waived due to the retrospective nature of the analysis; the information was obtained from anonymized medical charts and records.

Immunohistochemical staining and evaluation. All surgical specimens were fixed in $10 \%$ formaldehyde, embedded in paraffin, and cut into $3-\mu \mathrm{m}$ slices. After microwave antigen retrieval in citrate buffer $(\mathrm{pH}$ 6.0) the samples were incubated with anti-ATP7B rabbit antibody (Novus Biologicals, Littleton, CO. USA) (1:100 dilution) and mouse anti-O6-methylguanine-DNA methyltransferase monoclonal antibody (MGMT, Chemicon international, USA) (1:200 dilution) as the primary antibody. The cells in three microscopic fields (magnification $\mathrm{x} 400$ ) were counted independently by two researchers (M. F and S.Y). The criterion for a positive reaction was staining of a vesicle or vesicles in cytoplasm for ATP7B and clear nuclear staining for MGMT. The ratio of positive cells $(\%)$ was obtained by dividing the number of immunopositive cells by the total number of cells per field. The mean of six ratios of positive cells ( 2 readers, 3 fields each) was used for analysis. When more than $10 \%$ of the tumor cells were positive, the tumor was recorded as high-ATP7B GBM; tumors with less than $10 \%$ ATP7B-positive cells were categorized as low-ATP7B GBM. Anti-isocitrate dehydrogenase 1 (IDH1) R132H (Dianova GmbH, Hamburg, Germany) (1:50 dilution) was used as primary antibody following same immunohistochemical staining protocol mentioned above.

Cell culture and transfection. All cells were cultured in DMEM (Thermo Fisher Scientific, Grand Island, NE, USA) containing $10 \%$ fetal calf serum (Thermo Scientific,
Logan, UT, USA) and 100 units/ml antibiotic-antimycotic solution (Thermo Fisher Scientific) in $5 \% \mathrm{CO}_{2}$ at $37^{\circ} \mathrm{C}$. Wild type (WT) ATP7B-expressing cell lines (U251/WD-1 and U251/WD-2) were established by WT ATP7B transfection of the human glioblastoma cell line U251 using lipofectamin-2000 (ThermoFisher Scientific) as described previously (5). The control, U251/EV, was established from U251 cells transfected with vector (pRc/CMV) only.

Protein extraction and immunoblotting. Protein from cell lysates was prepared as described (9). The protein concentration was determined with the Bio-Rad protein assay kit according to the manufacturer's protocol (Bio-Rad Laboratories, Hercules, CA, USA). Total protein $(100 \mu \mathrm{g})$ was subjected to $7.5 \%$ SDS-PAGE under reducing conditions. Immunoblotting was as described elsewhere (10). The polyclonal anti-ATP7B antibody (Novus Biologicals, Littleton, CO, USA) or anti-GAPDH monoclonal antibody (Cell Signaling Technology, Danvers, MA, USA) was used as the primary antibody. Horseradish peroxidase-conjugated anti-rabbit IgG and anti-mouse IgG (GE Healthcare, Buckinghamshire, UK) were the secondary antibody respectively. Immunoreactive bands were visualized with enhanced chemiluminescence using the ECL prime Western blotting system (GE Healthcare).

Cell sutvival assay. Equal numbers of cells $\left(2 \times 10^{3}\right)$ were inoculated into each well of multi-well plates and treated for 7 days with TMZ (Sigma-Aldrich, St., Louis, MO, USA). Then their sensitivity to each of the administered TMZ dose was assessed by 3-(4,5-dimethylthiazol-2-yl)-2,5-diphenyl tetrazolium bromide (MTT) (Sigma-Aldrich) colorimetric 
A

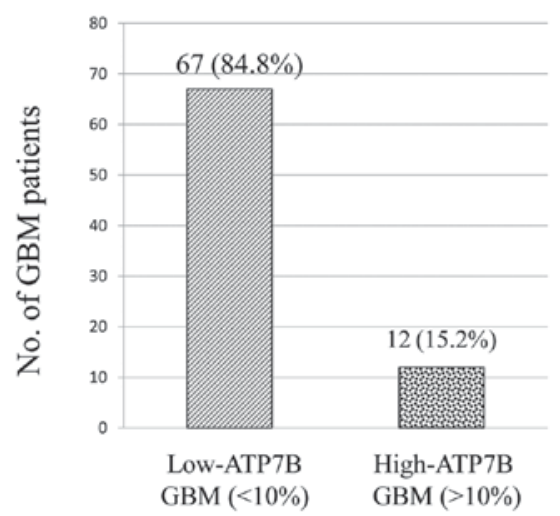

B

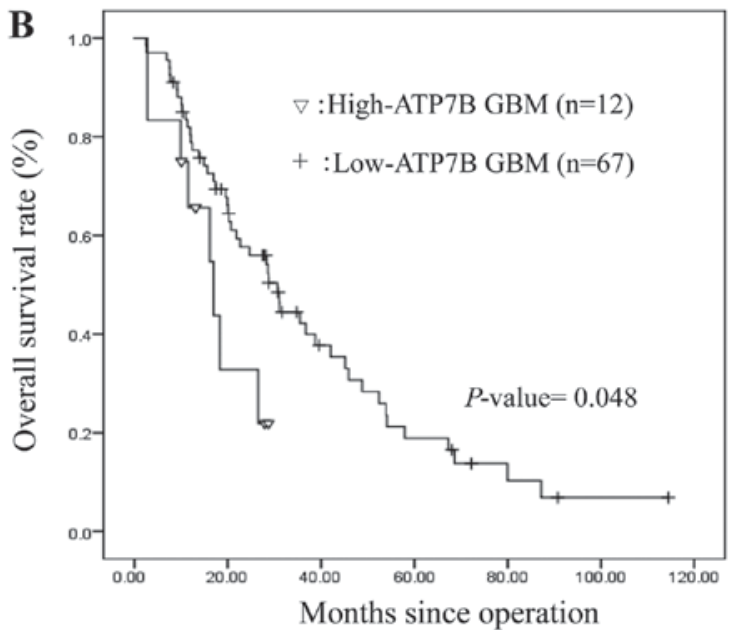

Figure 2. Prognostic value of the degree of ATP7B expression. (A) Number and proportion of GBM patients with low $(<10 \%)$ and high $(>10 \%)$ ATP7B-expressing tumors. (B) Kaplan-Meier curves comparing the overall survival of patients with high- and low-ATP7B-expressing GBM.
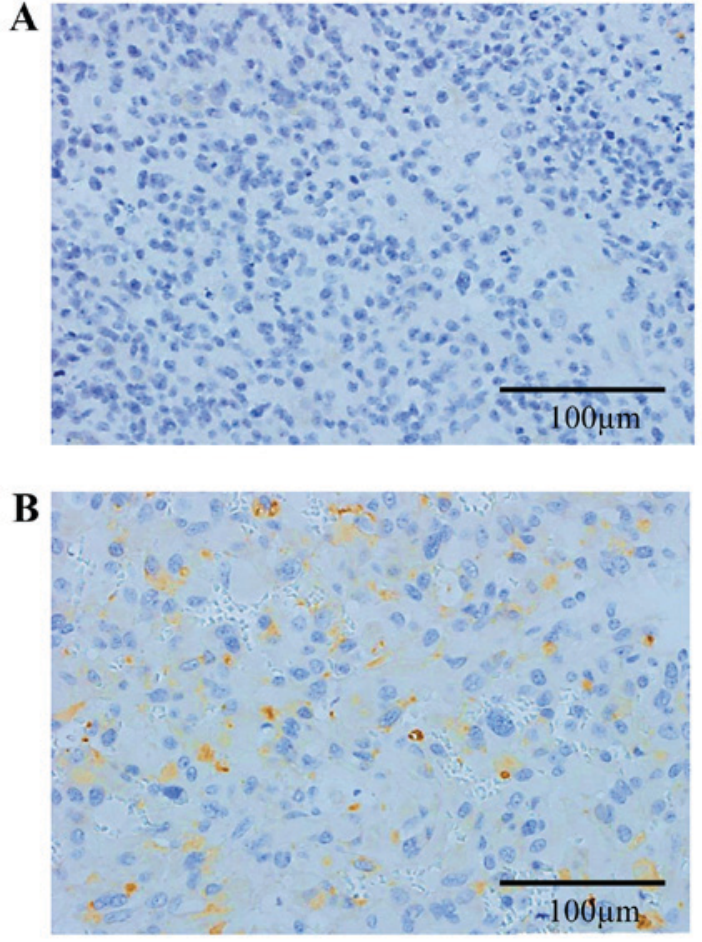

C

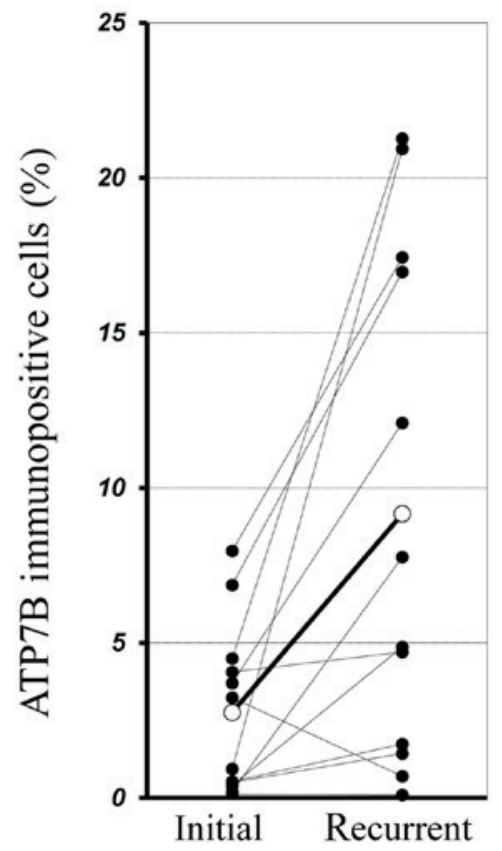

Figure 3. Immunohistochemical analysis of the expression of ATP7B in GBM that recurred after surgery and TMZ treatment (n=12). (A and B) Representative immunohistochemical staining of tissue samples obtained at the 1st (A) and 2nd GBM operation (B) from an identical patient (Bars indicate $100 \mu \mathrm{m}$ ). The ATP7B positivity ratio was $0.93 \pm 0.15 \%$ (A) and $20.93 \pm 7.79 \%$ (B). (C) Closed circles mean the percentage of ATP7B immunopositive cells in GBM specimens obtained at the 1st and the 2 nd operation (paired t-test, $\mathrm{P}<0.01$ ). Open circles indicate the mean value. The lines mean the tumor from same patients.

assay (9). The drug concentration that reduced the number of cells to $50 \%$ of cells grown in control medium was recorded as the $\mathrm{IC}_{50}$ value.

Statistical analysis. Data were analyzed using the Statistical Package for the Social Sciences (SPSS, v22; IBM, Armonk, NY, USA). For intergroup comparisons we used the Student t-test for continuous- and the Chi square test for categorical variables. Overall survival was plotted by applying Kaplan-Meier methods. Multivariable Cox proportional hazards regression analysis was used to obtain hazard ratios and $95 \%$ confidence intervals (CIs). Quantitative data were expressed as the mean $\pm \mathrm{SD} . \mathrm{P}<0.05$ was considered to indicate a statistically significant difference.

\section{Results}

ATP7B expression in human glioblastoma. In all $79 \mathrm{GBM}$ tissue samples obtained at the initial surgery, ATP7B expression were immunohistochemically assessed. The degree of cytoplasmic staining in tumor cells varied (Fig. 1A); the average rate of ATP7B protein expression was $4.4 \pm 0.98 \%$. Two representative 
Table I. ATP7B protein detection in Glioblastoma specimens: Correlation with clinical data.

\begin{tabular}{|c|c|c|c|c|}
\hline \multirow{2}{*}{$\begin{array}{l}\text { Correlatives } \\
\text { data }\end{array}$} & \multirow{2}{*}{$\begin{array}{c}\text { Specimens } \\
\text { No. }(\%)\end{array}$} & \multicolumn{2}{|c|}{$\begin{array}{c}\text { Immunohistochemical } \\
\text { expression of } \\
\text { ATP7B protien }\end{array}$} & \multirow[b]{2}{*}{ P-value } \\
\hline & & Low n $(\%)$ & High n (\%) & \\
\hline \multicolumn{5}{|l|}{ Sex } \\
\hline Male & $45(57.0)$ & $38(84.4)$ & $7(15.6)$ & 0.9 \\
\hline Female & $34(43.0)$ & $29(85.3)$ & $5(14.7)$ & \\
\hline \multicolumn{5}{|l|}{ Age (years) } \\
\hline$<50$ & $11(13.9)$ & $11(100)$ & $0(0)$ & 0.1 \\
\hline$>50$ & $68(79.7)$ & $56(82.4)$ & $12(17.6)$ & \\
\hline \multicolumn{5}{|c|}{ Tumor Location } \\
\hline Frontal & $27(34.2)$ & $26(96.3)$ & $1(3.7)$ & 0.2 \\
\hline Parital & $19(24.1)$ & $16(84.2)$ & $3(15.8)$ & \\
\hline Occipital & $3(3.8)$ & $3(100)$ & $0(0)$ & \\
\hline Temporal & $23(29.1)$ & $17(73.9)$ & $6(25.1)$ & \\
\hline Other & $7(8.9)$ & $5(71.4)$ & $2(28.6)$ & \\
\hline
\end{tabular}

P-value is obtain by Chi square test.

Table II. Chemosensitivity of ATP7B overexpressing cells.

\begin{tabular}{lccccc}
\hline Cells & $\mathrm{U} 251 / \mathrm{EV}$ & \multicolumn{2}{c}{$\mathrm{U} 251 / \mathrm{WD}-1$} & \multicolumn{2}{c}{$\mathrm{U} 251 / \mathrm{WD}-2$} \\
\hline Agent & $\mathrm{IC}_{50}$ & $\mathrm{IC50}$ & $\mathrm{RR}^{\mathrm{a}}$ & $\mathrm{IC}_{50}$ & $\mathrm{RR}^{\mathrm{a}}$ \\
$\mathrm{TMZ}(\mu \mathrm{M})$ & $61 \pm 4.8$ & $240 \pm 59$ & 3.84 & $110 \pm 21$ & 1.71 \\
\hline
\end{tabular}

$\mathrm{IC}_{50}$ values are means \pm SDs from triplicate determinations with MTT assay. TMZ, Temozolomide, RR (relative resistance) is a value that $\mathrm{IC}_{50}$ for U251/WD-1 or U251/WD-2 divided with IC50 for U251/EV

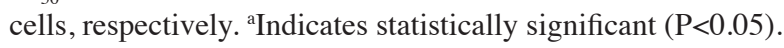

cases of GBM tumors exhibiting high (>10\%) and low ATP7B expression $(<10 \%)$ are shown in Fig. 1B and C, respectively.

Prognostic relevance of ATP7B expression. Of our 79 patients, $12(15.2 \%)$ harbored high-ATP7B GBM; $14.4 \pm 3.0 \%$ of the tumor cells were ATP7B positive. The other 67 patients had low-ATP7B GBM; $2.6 \pm 0.64 \%$ of the cells were ATP7B positive (Fig. 2A). Investigation of the relationship between patient characteristics and ATP7B expression revealed no significant association with the patient gender and age, and the GBM tumor location. None of our patients younger than 50 years bore high-ATP7B GBM (Table I). The Kaplan-Meier estimate of overall survival in Fig. 2B was significantly shorter in patients with high-ATP7B GBM (hazard ratio $0.452,95 \% \mathrm{CI}$ $0.206-0.994, \mathrm{P}=0.048$ ). The median overall survival of patients with high- and low ATP7B GBM was 14.6 and 24.7 months, respectively. In addition, the MGMT expression in low-ATP7B GBM ( $5.7 \pm 1.2 \%)$ and high-ATP7B GBM (5.3 $\pm 1.3 \%)$ has no significant difference. IDH1 mutant is negative in all 79 GBM cases.

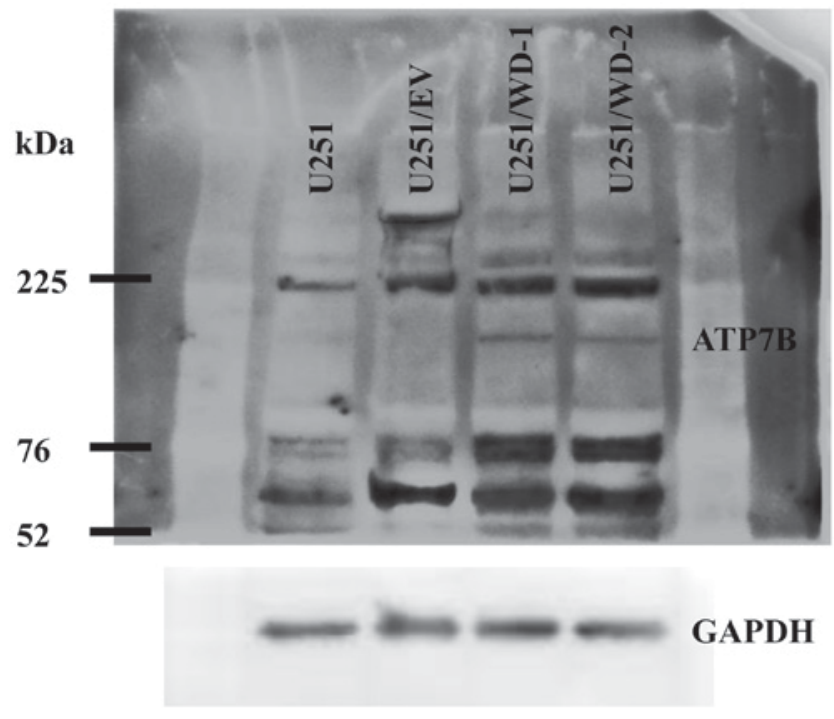

Figure 4. Immunoblots of ATP7B proteins in lysates of the indicated cell lines. GAPDH protein was shown as a loading control. ATP7B of $165 \mathrm{kDa}$ bands were detected in U251/WD-1 cells and U251/WD-2 cells.

$A T P 7 B$ expression in recurrent GBMs after treatment with TMZ. Of our 79 patients, 12 underwent the second operation due to the recurrence. Fig. 3A and B show the immunohistochemical staining for ATP7B of tissues removed at the 1 st and 2 nd surgical procedure from the identical patient. In this representative case, the mean ATP7B positivity ratio was $0.93 \pm 0.15 \%$ and $20.93 \pm 7.79 \%$ in samples from the 1 st and 2 nd operation, respectively. In all 12 recurrent cases the expression of ATP7B in the 2nd surgical samples was significantly higher than the 1 st ones $(9.17 \pm 2.56 \%$ vs. $2.75 \pm 0.55 \%, \mathrm{P}=0.008$ by the paired t-test) (Fig. 3C).

Expression of $A T P 7 B$ expressing GBM cells were resistant to TMZ. We detected ATP7B $165 \mathrm{kDa}$ bands in the both transfected cell lines but not in U251 and U251/EV cells by immunoblotting (Fig. 4). Lower bands (105 kDa) are likely to be specifically digested ATP7B protein.

The sensitivity of the transfected cells to TMZ was evaluated by MTT assay. Interestingly, U251/WD-1 cells and U251/WD-2 cells were 3.8 and 1.7 times more resistant to TMZ than U251/EV cells (Table II), indicating that the resistance to TMZ was correlated with ATP7B expression in these cells.

\section{Discussion}

GBM resistance mechanisms to alkylating agents, e.g. O6-methylguanine-DNA methyltransferase (MGMT), isocitrate dehydrogenase (IDH1/2), Y-box binding protein-1 (YB-1), and maternal embryonic leucine-zipper kinase (MELK) have been identified (11-14). Recently we reported that ATP7B confers drug resistance against several structurally unrelated chemotherapeutic agents through drug sequestration in acidic vesicles (5). We expected ATP7B as a candidate protein for the mediation of chemoresistance to TMZ. P-type ATPase copper transporters ATP7A and ATP7B play key roles in regulating copper homeostasis. Their function is directly influenced by their subcellular localization. ATP7A 
is ubiquitously expressed and ATP7A mutations elicit Menkes disease (15); ATP7B is primarily expressed in the liver and mutant ATP7B is involved in Wilson disease $(16,17)$. ATP7A and ATP7B are expressed in normal brain tissue, especially in the polarized epithelial tissue of the choroid plexus; they are also observed in the visual cortex, anterior cingulate cortex, caudate putamen, and cerebellum (18).

The high expression of ATP7B protein has been shown in human ovarian-, gastric-, and breast cancer (6-8). We earlier reported that ATP7A and ATP7B were involved in multi-drug resistance $(5,19)$ Highly expressed ATP7B is a poor prognostic marker in patients with ovarian and oral squamous cell cancers treated with cisplatin-based chemotherapy $(6,20)$. In the present study we first document the presence of different levels of ATP7B expression in GBM tissues. We also report that the prognosis of patients with ATP7B high-expressing tumors was poorer than of patient with low ones. We included only patients who underwent total tumor removal to exclude the influence of different degree of surgical removal. We regard the standardizing sample back ground is very important to estimate the correct influence of ATP7B on patient survival. The patients with residual tumor after surgery were excluded because these patients must bring heterogeneity in treatment affecting on the survival. We also found that MGMT and IDH1 had no significant influence in these particular groups. Postoperative adjuvant therapy, including radio- and chemotherapy, was administered under the same protocol to all 79 patients. As the patient gender and age, and the tumor location exhibited no significant relationship with ATP7B expression, its elevation in patients with GBM can serve as a marker for a poor prognosis.

We also found that GBM that recurred after treatment with TMZ and radiotherapy exhibited higher ATP7B expression than the initially operated tumor. This observation consistent with the ideas that adjuvant therapy induced the higher expression of ATP7B and ATP7B overexpressing rendered GBM cells resistant to TMZ.

Others reported that ATP-dependent drug efflux mechanisms involving $\mathrm{P}$-glycoprotein (P-gp, ABCB1), breast cancer-resistance protein1 (BCRP1, ABCG2), and multidrug-resistance-associated proteins (MRPs, ABCC1) confer drug resistance to gliomas (21). P-gp and BCRP1 are mainly expressed in endothelial cells of the tumor vasculature instead of the glioma cells themselves $(22,23)$ and both are also present at comparable levels in the normal brain (24). Thus, chemotherapeutic agents that inhibit P-gp and BCRP1 functions may be more toxic in normal tissues than neoplastic ones, thereby precluding an acceptable clinical response. As ATP7B was abundant in GBM cells, cellular micro-environmental modifications targeting ATP7B may help to abate their drug resistance. We reported that the drug resistance of an ATP7B over-expressing epidermoid carcinoma cell line could be controlled by increasing the endo-lysosomal pH level (5). This finding may lead to the development of a drug delivery procedure that targets acidic vesicles and helps to overcome the ATP7B-mediated drug resistance of GBM cells.

In the present study we indicated ATP7B expressing U251 cells are more resistant to TMZ. However there are possibilities such effects cannot be observed in some other cells, since the cancer cells have different genetic background. The further studies are needed to make clear the effect of ATP7B expression in other GBM cell lines and identify important back ground factors. Our investigation of the expression of ATP7B in GBM strongly suggests that ATP7B plays a role in TMZ resistance. Studies are underway to identify the mechanism(s) implicated in the acquisition of drug resistance and to develop specific maneuvers to overcome the ATP7B-mediated drug resistance of glioblastoma.

\section{Acknowledgements}

The authors thank Ms. Tomoko Takajyo for performing the immunostaining. The present study was supported by JSPS KAKENHI grant nos. JP15K10338, JP26870456, JP16K07121.

\section{References}

1. Thakkar JP, Dolecek TA, Horbinski C, Ostrom QT, Lightner DD, Barnholtz-Sloan JS and Villano JL: Epidemiologic and molecular prognostic review of glioblastoma. Cancer Epidemiol Biomarkers Prev 23: 1985-1996, 2014.

2. Stupp R, Mason WP, van den Bent MJ, Weller M, Fisher B, Taphoorn MJ,BelangerK,Brandes AA,MarosiC,BogdahnU,etal: Radiotherapy plus concomitant and adjuvant temozolomide for glioblastoma. N Engl J Med 352: 987-996, 2005.

3. Verhoeff JJ, van Tellingen O, Claes A, Stalpers LJ, van Linde ME, Richel DJ, Leenders WP and van Furth WR: Concerns about anti-angiogenic treatment in patients with glioblastoma multiforme. BMC Cancer 9: 444, 2009.

4. Ohka F, Natsume A and Wakabayashi T: Current trends in targeted therapies for glioblastoma multiforme. Neurol Res Int 2012: 878425, 2012.

5. Moinuddin FM, Shinsato Y, Komatsu M, Mitsuo R, Minami K, Yamamoto M, Kawahara K, Hirano H, Arita K and Furukawa T: ATP7B expression confers multidrug resistance through drug sequestration. Oncotarget 7: 22779-22790, 2016.

6. Nakayama K, Kanzaki A, Terada K, Mutoh M, Ogawa K, Sugiyama T, Takenoshita S, Itoh K, Yaegashi N, Miyazaki K, et al: Prognostic value of the $\mathrm{Cu}$-transporting ATPase in ovarian carcinoma patients receiving cisplatin-based chemotherapy. Clin Cancer Res 10: 2804-2811, 2004

7. Kanzaki A, Toi M, Neamati N, Miyashita H, Oubu M, Nakayama K, Bando H, Ogawa K, Mutoh M, Mori S, et al: Copper-transporting P-type adenosine triphosphatase (ATP7B) is expressed in human breast carcinoma. Jpn J Cancer Res 93: 70-77, 2002.

8. Ohbu M, Ogawa K, Konno S, Kanzaki A, Terada K, Sugiyama T and Takebayashi Y: Copper-transporting P-type adenosine triphosphatase (ATP7B) is expressed in human gastric carcinoma. Cancer Lett 189: 33-38, 2003.

9. Shinsato Y, Furukawa T, Yunoue S, Yonezawa H, Minami K, Nishizawa Y, Ikeda R, Kawahara K, Yamamoto M,Hirano H, et al: Reduction of MLH1 and PMS2 confers temozolomide resistance and is associated with recurrence of glioblastoma. Oncotarget 4: 2261-2270, 2013.

10. Che XF, Zheng CL, Owatari S, Mutoh M, Gotanda T, Jeung HC, Furukawa T, Ikeda R, Yamamoto M, Haraguchi $\mathrm{M}$, et al: Overexpression of survivin in primary ATL cells and sodium arsenite induces apoptosis by down-regulating survivin expression in ATL cell lines. Blood 107: 4880-4887, 2006.

11. Joshi K, Banasavadi-Siddegowda Y, Mo X, Kim SH, Mao P, Kig C, Nardini D, Sobol RW, Chow LM, Kornblum HI, et al: MELK-dependent FOXM1 phosphorylation is essential for proliferation of glioma stem cells. Stem Cells 31: 1051-1063, 2013.

12. Hegi ME, Diserens AC, Gorlia T, Hamou MF, de Tribolet N, Weller M, Kros JM, Hainfellner JA, Mason W, Mariani L, et al: MGMT gene silencing and benefit from temozolomide in glioblastoma. N Engl J Med 352: 997-1003, 2005.

13. Yang $\mathrm{P}$, Zhang W, Wang Y, Peng X, Chen B, Qiu X, Li G, Li S, Wu C, Yao K, et al: IDH mutation and MGMT promoter methylation in glioblastoma: Results of a prospective registry. Oncotarget 6: 40896-40906, 2015. 
14. Gao Y, Fotovati A, Lee C, Wang M, Cote G, Guns E, Toyota B, Faury D, Jabado $\mathrm{N}$ and Dunn SE: Inhibition of Y-box binding protein-1 slows the growth of glioblastoma multiforme and sensitizes to temozolomide independent O6-methylguanine-DNA methyltransferase. Mol Cancer Ther 8: 3276-3284, 2009.

15. Vulpe C, Levinson B, Whitney S, Packman S and Gitschier J: Isolation of a candidate gene for Menkes disease and evidence that it encodes a copper-transporting ATPase. Nat Genet 3: 7-13, 1993.

16. Bull PC, Thomas GR, Rommens JM, Forbes JR and Cox DW: The Wilson disease gene is a putative copper transporting P-type ATPase similar to the Menkes gene. Nat Genet 5: 327-337, 1993.

17. Tanzi RE, Petrukhin K, Chernov I, Pellequer JL, Wasco W, Ross B, Romano DM, Parano E, Pavone L, Brzustowicz LM, et al: The Wilson disease gene is a copper transporting ATPase with homology to the Menkes disease gene. Nat Genet 5: 344-350, 1993.

18. Davies KM, Hare DJ, Cottam V, Chen N, Hilgers L, Halliday G, Mercer JF and Double KL: Localization of copper and copper transporters in the human brain. Metallomics 5: 43-51, 2013.

19. Owatari S, Akune S, Komatsu M, Ikeda R, Firth SD, Che XF, Yamamoto M, Tsujikawa K, Kitazono M, Ishizawa T, et al: Copper-transporting P-type ATPase, ATP7A, confers multidrug resistance and its expression is related to resistance to $\mathrm{SN}-38$ in clinical colon cancer. Cancer Res 67: 4860-4868, 2007.
20. Miyashita H, Nitta Y, Mori S, Kanzaki A, Nakayama K, Terada K, Sugiyama T, Kawamura H, Sato A, Morikawa H, et al: Expression of copper-transporting P-type adenosine triphosphatase (ATP7B) as a chemoresistance marker in human oral squamous cell carcinoma treated with cisplatin. Oral Oncol 39: $157-162,2003$

21. Veringa SJ, Biesmans D, van Vuurden DG, Jansen $M H$, Wedekind LE, Horsman I, Wesseling P, Vandertop WP, Noske DP, Kaspers GJ and Hulleman E: In vitro drug response and efflux transporters associated with drug resistance in pediatric high grade glioma and diffuse intrinsic pontine glioma. PLoS One 8: e61512, 2013

22. Henson JW, Cordon-Cardo C and Posner JB: P-glycoprotein expression in brain tumors. J Neurooncol 14: 37-43, 1992.

23. Sawada T, Kato Y, Sakayori N, Takekawa Y and Kobayashi M: Expression of the multidrug-resistance P-glycoprotein (Pgp, MDR-1) by endothelial cells of the neovasculature in central nervous system tumors. Brain Tumor Pathol 16: 23-27, 1999.

24. Daood M, Tsai C, Ahdab-Barmada M and Watchko JF: ABC transporter (P-gp/ABCB1, MRP1/ABCC1, BCRP/ABCG2) expression in the developing human CNS. Neuropediatrics 39: 211-218, 2008. 